\title{
TINGKAT VOLUME OKSIGEN MAKSIMAL ATLET CABOR KONSENTRASI UNGGULAN SENAM PUSLATKOT KOTA KEDIRI DALAM MENGHADAPI PEKAN OLAHRAGA PROVINSI 2022
}

\author{
Puspodari \\ Universitas Nusantara PGRI Kediri \\ E-mail: puspodari@unpkdr.ac.id \\ DOI: https://doi.org/10.36526/kejaora.v6i1.1296
}

\begin{abstract}
ABSTRAK
Senam merupakan salah satu cabang olahraga yang melibatkan performa gerakan yang membutuhkan kekuatan, kecepatan, keserasian gerakan fisik yang teratur dan daya tahan. Salah satu usaha untuk mendukung dan meningkatkan performa atlet sebelum bertanding adalah dengan mengadakan evaluasi pada kondisi fisik atlet. Kondisi fisik atlet perlu disiapkan secara matang agar performa atlet dapat ditampilkan secara maksimal. Salah satu kondisi fisik yang diperlukan atlet senam adalah daya tahan aerobik maksimal atau yang sering disebut volume oksigen maksimal $\left(\mathrm{VO}_{2} \mathrm{Max}\right)$. Tujuan penelitian ini adalah untuk mengetahui tingkat kemampuan volume oksigen maksimal $\left(\mathrm{VO}_{2} \mathrm{Max}\right)$ atlet senam PUSLATKOT kota Kediri dalam menghadapi Pekan Olahraga Provinsi tahun 2022. Metode dalam penelitian ini menggunakan pendekatan deskriptif kuantitatif dengan jenis penelitian non eksperiment. Populasi dalam penelitian ini adalah semua atlet senam yang tergabung dalam Pusat Latihan Kota (PUSLATKOT) kota Kediri yang berjumlah 13 atlet. Instrumen pengumpulan data menggunakan Multistage Fitness Test (MFT). Hasil nilai tingkat kemampuan volume oksigen maksimal atlet senam PUSLATKOT kota Kediri sejumlah 2 atlet dengan prosentase 15,39\% dalam kategori baik, 4 atlet dengan prosentase 30,77\% dalam kategori cukup, 7 atlet dengan prosentase $53,84 \%$ dalam kategori kurang.
\end{abstract}

Kata Kunci: Kondisi Fisik, VO2Max, Senam

\section{PENDAHULUAN}

Olahraga adalah suatu bentuk aktivitas fisik yang terencana dan terstruktur yang melibatkan gerakan tubuh berulangulang dan ditunjukkan untuk meningkatkan kebugaran jasmani. Olahraga sangat bermanfaat bagi kesehatan dan dapat meningkatkan derajat kesehatan, olahraga itu sendiri merupakan kebutuhan pokok dalam kehidupan kita sehari-hari.

Olahraga adalah berbagai gerak tubuh yang dirangkai secara teratur dan terencana dengan tujuan untuk menjaga dan meningkatkan kualitas hidup serta mencapai kemampuan jasmani. Selain meningkatkan kebugaran fisik, olahraga juga bisa memperbaiki dan meningkatkan kinerja otak manusia sehingga dapat bekerja lebih baik dan meningkatkan rasa percaya diri seseorang (Giriwijoyo, 2013). Berdasarkan tujuan dan fungsinya, macam-macam olahraga terdiri dari olahraga pendidikan, olahraga rekreasi dan olahraga kesehatan. Olahraga prestasi adalah aktivitas olahraga yang pengelolaannya dilakukan secara profesional dalam rangka meningkatkan dan mendapatkan prestasi yang maksimal pada cabang olahraga tertentu. Pembinaan dan pengembangan potensi atlet untuk mendapatkan prestasi maksimal juga harus dikelola secara profesional (Puspodari \& Muharram, 2018)

Bentuk usaha untuk mendukung dan meningkatkan performa atlet sebelum bertanding adalah dengan mengadakan evaluasi kondisi fisik atlet. kondisi atlet perlu disiapkan secara terencana dan matang agar performa atlet dapat maksimal. Prestasi optimal dalam olahraga akan tercapai apabila latihan yang dilakukan berkualitas dan menganut konsep pembinaan paramida. Prestasi maksimal akan tercapai jika dalam 
Jurnal Kejaora: Jurnal Kesehatan Jasmani dan Olah Raga

ISSN: 2541-5042 (Online)

ISSN: 2503-2976 (Print)

Volume 6 Nomor 1, Edisi April 2021

jiwa seorang atlet ada suatu tuntutan untuk mencapai kesuksesan (Utami, 2015)

Prestasi olahraga tidak terlepas dari unsur kondisi fisik. Peningkatan kondisi fisik atlet bertujuan untuk agar kemampuan fisik menjadi prima dan berguna menunjang aktivitas olahraga dalam rangka mencapai prestasi prima. Kondisi fisik merupakan suatu hal yang cukup mendasar untuk menentukan suatu prestasi olahraga (Mulyadi \& Nikon, 2019). Kondisi fisik ditinjau dari segi faalnya adalah kemampuan seseorang dapat diketahui sampai sejauh mana kemampuanya sebagai pendukung aktivitas menjalankan olahraga (Wiwoho et al., 2014)

Kondisi fisik adalah kemampuan seseorang untuk memfungsikan organ-organ tubuh dalam melakukan segala aktivitas fisik dan satu kesatuan utuh dari komponenkomponen yang tidak bisa dipisahkan (Musrifin Bausad, 2020). Menurut (Supriyoko \& Mahardika, 2018) kondisi fisik merupakan hal mutlak yang wajib dimiliki oleh atlet di dalam mengembangkan dan meningkatkan prestasi olahraga yang optimal, sehingga segenap kondisi fisiknya harus dikembangkan dan ditingkatkan. Berdasarkan pendapat tersebut, maka wajib bagi atlet untuk memantau kondisi fisiknya masing-masing guna mencapai prestasi yang setinggi-tingginya

Senam merupakan cabang olahraga yang dalam permainannya membutuhkan gerakan-gerakan yang sangat komplek, tentunya untuk menunjang kebutuhan tersebut dibutuhkan ketahanan kardiorespirasi. Pada dasarnya ketahanan kardiorespirasi dibagi menjadi dua yaitu aerobik dan anaerobik. Pengukuran ketahanan kardio respiratory untuk kapasitas aerobik dapat dilakukan dengan cara mengukur konsumsi oksigen maksimal $\left(\mathrm{VO}_{2} \mathrm{Max}\right)$.

Senam merupakan cabang olahraga konsentrasi yang memerlukan flexibilitas, konsentrasi, koordinasi dan daya tahan didalam prosesnya. Cabang olahraga senam di kota Kediri merupakan cabang olahraga konsentrasi unggulan yang dipromosikan dalam event-event yang bergengsi, salah satu program pembinaan atlet dikota Kediri adalah PUSLATKOT (pusat pelatihan kota)

yang didalamnya terdapat atlet-atlet terbaik kota Kediri yang dipilih berdasarkan rekap data hasil yang pernah diperoleh. Atlet-atlet PUSLATKOT salah satunya dipersiapkan untuk mengikuti pekan olahraga Jawa timur yang digelar setiap dua tahun sekali.

Pekan Olahraga Provinsi (Porprov), mengharapkan atlet dan pelatih kota Kediri mampu memperoleh prestasi maksimal. Perolehan medali pada ajang pekan olahraga provinsi yang lalu menorehkan catatan menarik bagi kota Kediri dengan raihan medali yang mengharumkan nama kota Kediri. Saat ini, atlet-atlet kota Kediri cukup mempunyai kedudukan/ posisi yang membanggakan di ajang Pekan Olahraga Provinsi. Sehingga tim monev KONI kota Kediri harus memantau dengan ketat kondisi fisik atlet yang telah dipersiapkan dalam Pekan olahraga Provinsi

Dalam rangka mendukung dan meningkatkan performa atlet sebelum bertanding maka KONI Kota Kediri secara aktif memantau latihan dan kondisi fisik atlet yang akan berlaga pada pekan olahraga provinsi tahun 2022. Karena kondisi fisik atlet perlu disiapkan secara matang agar performa atlet dapat ditampilkan secara maksimal saat bertanding maka pelatih perlu mendesain program latihan.

Salah satu kondisi fisik yang diperlukan atlet senam adalah daya tahan aerobik atau yang sering disebut volume oksigen maksimal $\left(\mathrm{VO}_{2} \mathrm{Max}\right)$. Kemampuan otot dalam melakukan kerja akan semakin lama jika nilai $\mathrm{VO}_{2} \mathrm{Max}$ nya tinggi, sebaliknya jika semakin rendah nilai $\mathrm{VO}_{2}$ Max maka otot akan menjadi cepat lelah. Maka, kondisi fisik atlet senam PUSLATKOT kota Kediri sangat mempengaruhi dalam performa saat bertanding.

$\mathrm{VO}_{2} \mathrm{Max}$ merupakan kemampuan seseorang untuk menghirup dan menggunakan oksigen secara maksimal dalam melakukan aktivitas atau kegiatan olahraga hingga mengalami kelelahan. $\mathrm{VO}_{2} \mathrm{Max}$ diartikan juga penggunaan oksigen maksimal adalah tempo tercepat dimana seseorang dapat menggunakan oksigen selama berolahraga. $\mathrm{VO}_{2} \mathrm{Max}$ disebut juga dengan maximal oxigen intake dan maximal oxygen power yang menunjukkan perbedaan 
Jurnal Kejaora: Jurnal Kesehatan Jasmani dan Olah Raga

ISSN: 2541-5042 (Online)

ISSN: 2503-2976 (Print)

Volume 6 Nomor 1, Edisi April 2021

yang terbesar antara oksigen yang dihisap masuk ke dalam paru oksigen yang dihembuskan keluar paru. Dengan kemampuan kapasitas volume oksigen maksimal yang baik, maka akan sangat menguntungkan bagi atlet senam, sebab jika atlet senam memiliki kapasitas aerobik yang baik maka atlet tidak akan mudah lelah karena oksigen yang dibutuhkan sudah tersedia didalam tubunya.

Salah satu cara untuk menilai daya tahan kardiorespirasi seseorang yaitu dengan mengukur nilai VO2max dengan tujuan mengukur kapasitas jantung, paru, dan darah untuk mengangkut oksigen ke otot yang bekerja dan mengukur penggunaan oksigen oleh otot (Nugraheni et al., 2017). Teknik pengukuran dilakukan dengan pengukuran daya tahan menggunakan instrumen tes MFT (Multistage Fitness Test).

Tujuan utama dalam tes kondisi fisik khusus adalah untuk memperdalam perkembangan unsur- unsur kondisi fisik yang lebih spesifik sesuai dengan tuntutan cabang olahraga (Amin \& Adnan, 2020). Kebutuhan kondisi fisik tersebut tidak dapat disamakan untuk masing-masing cabang olahraga, karena setiap cabang olahraga memiliki karakteristik gerak tersendiri (Wibisana et al., 2016). Oleh karena itu apabila seorang atlet ingin mencapai prestasi yang maksimal, maka faktor kondisi fisik secara bersamaan pun harus ditingkatkan (Syukur et al., 2019).

Berdasarkan beberapa teori pendukung yang telah disampaikan maka hal yang perlu ditekankan pada penelitian ini hal pentingnya tingkat kondisi fisik khususnya kemampuan volume oksigen maksimal pada atlet senam dengan pengukuran dengan instrumen Multistage Fitness Test (MFT) atlet senam PUSLATKOT Kota Kediri.

\section{METODE}

Penelian ini menggunakan pendekatan kuantitatif yang menenkankan pada penilaian data angka objek yang sedang diamati, teknik yang digunakan adalah teknik deskriptif sehingga tidak menggunakan pengujian hipotesis. Tujuan dalam penelitian ini mengevaluasi dan menganalisis tingkat $\mathrm{VO}_{2} \mathrm{Max}$ atlet PUSLATKOT kota Kediri

cabang olahraga senam sebelum menghadapi pekan olahraga provinsi. Metode yang digunakan adalah metode survei dengan teknik tes dan pengukuran. Sampel dalam penelitian ini adalah seluruh atlet PUSLATKOT cabang olahraga senam yang berjumlah 13 orang. Instrumen yang digunakan adalah Multitasge Fitness Tess (MFT) atau bleep test. Data yang diperoleh akan dideskripsikan kemudian dianalisis. Penelitian ini menggambarkan kondisi tingkat $\mathrm{VO}_{2} \mathrm{Max}$ atket senam PUSLATKOT kota Kediri dalam menghadapi pekan olahraga provinsi 2022.

\section{HASIL DAN PEMBAHASAN}

Deskripsi data penelitian berikut ini bertujuan untuk menggambarkan data peneltian dari subjek yang diteliti, yaitu hasil tes kemampuan VO2Max yang diukur dengan menggunakan tes MFT atau bleep test. Adapun deskripsi data kemampuan volume oksigen maksimal atlet senam PUSLATKOT kota Kediri adalah sebagai berikut:

Tabel 1 : Nilai Prosentase

$\begin{array}{ll}\text { Kategori } & \text { Prosentase Jumlah } \\ (\%)\end{array}$

\begin{tabular}{lll}
\hline Baik Sekali & $0 \%$ & 0 \\
\hline Baik & $15,39 \%$ & 2 \\
\hline Cukup & $30,77 \%$ & 4 \\
\hline Kurang & $53,84 \%$ & 7 \\
\hline $\begin{array}{l}\text { Kurang } \\
\text { Sekali }\end{array}$ & $0 \%$ & 0 \\
\hline
\end{tabular}

Nilai prosentase pada tabel diatas menunjukkan bahwa tingkat kondisi fisik yaitu kemampuan volume oksigen maksimal atlet senam dengan jumlah responden 2 orang, masuk dalam kategori baik, sejumlah 0 atlet $(0 \%)$ dalam kategori baik sekali sejumlah 4 atlet $(30,77 \%)$ dalam kategori cukup, sejumlah 7 atlet $(53,84 \%)$ dalam kategori kurang. Berikut ini merupakan tabel persentase tingkat VO2Max mengacu pada norma Brianmac. 
Jurnal Kejaora: Jurnal Kesehatan Jasmani dan Olah Raga

ISSN: 2541-5042 (Online)

ISSN: 2503-2976 (Print)

Volume 6 Nomor 1, Edisi April 2021

Tabel 2. Deskripsi Persentase Klasifikasi Tes $\mathrm{VO}_{2} \operatorname{Max}$ (Brianmac, 2012)

\begin{tabular}{lll}
\hline No & Nilai & Kategori \\
\hline 1 & $\geq 52,4$ & Luar Biasa \\
\hline 2 & $46,5-52,4$ & Sangat Baik \\
\hline 3 & $42,5-46,4$ & Baik \\
\hline 4 & $36,5-42,4$ & Sedang \\
\hline 5 & $33,0-36,4$ & Kurang \\
\hline 6 & $\leq 33,0$ & Sangat Kurang \\
\hline
\end{tabular}

Berdasarkan analisis data hasil kemampuan volume oksigen maksimal dengan menggunakan instrumen tes multistage fitness test (MFT) pada atlet PUSLATKOT cabang olahraga senam, dapat dikemukakan bahwa prosentase terbesar berada dalam kategori kurang dengan persentase $53,84 \%$ sejumlah 7 atlet. Hal tersebut perlu menjadi sorotan dan perhatian lebih bagi pelatih, dikarenakan kemampuan volume oksigen maksimal sangat dibutuhkan dalam cabang olahraga senam. Sebagaimana berdasarkan hasil penelitian bahwa untuk memperoleh hasil yang optimal ketika senam dengan beberapa koregrafi, dibutuhkan kemampuan volume oksigen maksimal yang tinggi, karena konsentrasi sangat diperlukan ketika pertandingan senam berlangsung.

Konsentrasi yang baik ditunjang dengan kondisi daya tahan kardiovaskuler yang baik. Terdapat beberapa gerakan dalam olahraga senam yang membutuhkan optimalisasi kemampuan oksigen maksimal. Diantaranya adalah ketika seorang atlet melakukan gerakan koreografi, dengan gerakan dengan tingkat kesulitan yang tinggi. Oleh karena itu, untuk mempersiapkan atlet menghadapi event PORPROV 2022 maka pelatih diharapkan mampu memberikan sebuah program latihan yang berorientasi untuk meningkatkan kemampuan volume oksigen para atlet senam.

Teknik analisis data yang digunakan dalam penelitian ini adalah deskriptif kuantitatif dengan cara mengambil data dari atlet senam PUSLATKOT kota Kediri dengan tes dan pengukuran memalui MFT, kemudian dikonversikan ke dalam tabel norma tes $\mathrm{VO}_{2} \mathrm{Max}$ atlet senam PUSLATKOT kota Kediri. Untuk mengklasifikasikan seberapa 
Jurnal Kejaora: Jurnal Kesehatan Jasmani dan Olah Raga

ISSN: 2541-5042 (Online)

ISSN: 2503-2976 (Print)

Volume 6 Nomor 1, Edisi April 2021

Dalam rangka menjaga kondisi fisik atlet yang tentu didalamnya terdapat volume oksigen maksimal atau sering disebut juga daya tahan jantung dan paru,diperlukan program latihan yang memuat program daya tahan kardiovaskuler didalamnya. Latihan bisa diberikan dengan pembebanan dan intensitas yang telah disesuaikan. Latihan dapat berjalan sesuai program apabila kondisi $\mathrm{VO}_{2} \mathrm{Max}$ atlet baik. Nilai pengukuran $\mathrm{VO}_{2} \mathrm{Max}$ dapat dijadikan acuan untuk pemberian program latihan yang baik dan sesuai.

Berdasarkan hasil pengukuran yang telah didapatkan peneliti. Diperlukan program latihan yang fokus pada daya tahan kardiovaskuler sehingga dapat meningkatkan nilai $\mathrm{VO}_{2} \mathrm{Max}$ yang masih kurang. Saran peneliti terutama bagi para guru, pelatih serta dosen yang membidangi kepelatihan khususnya sebaiknya dalam hal melatih dapat memberikan porsi khusus dalam latihan kondisi fisik sesuai dengan komponen kondisi fisik yang diperlukan seperti kelincahan tubuh, kecepatan, daya tahan dan konsentrasi.

\section{DAFTAR PUSTAKA}

Amin, H., \& Adnan, A. (2020). Studi Tentang Beberapa Komponen Kondisi Fisik Atlet Bolavoli SMK Negeri 1 Kota Solok. Jurnal Patriot, 2(1), 265-276.

Brian Mac. (2018) Circuit Training. Diakses pada https://www.bri anmac.co.uk/circuit.htm. (Online) September

Giriwiyono, S dan Sidik, D. Z (2013). Ilmu Faal Olahraga untuk

Mulyadi, H., \& Nikon, B. (2019). Tinjauan Kondisi Fisik Atlet Bola Basket. JurnalPendidikan Jasmani Dan Olahraga, 2(2), 26-32.

Musrifin, A. Y., \& Bausad, A. A. (2020). Analisis Unsur Kondisi Fisik Pemain Sepak Bola Mataram Soccer Akademi NTB. Jurnal IImiah Mandala Education, 6(1), 113-119.

Nugraheni, H. D., Marijo, \& Indraswari, D. A. (2017). Perbedaan Nilai VO2Max Antara Atlet Cabang Olahraga Permainan Dan Bela Diri. Jurnal Kedokteran Diponegoro, 6(2), 622- 